\title{
Non-unions treated with bone morphogenic protein 7: introducing the quantitative measurement of human serum cytokine levels as promising tool in evaluation of adjunct non-union therapy
}

Arash Moghaddam ${ }^{1 *}$, Lisa Breier ${ }^{2}$, Patrick Haubruck ${ }^{1}$, Daniel Bender ${ }^{3}$, Bahram Biglari $^{4}$, Andreas Wentzensen ${ }^{5}$ and Gerald Zimmermann ${ }^{6}$

\begin{abstract}
Background: In this study we sought to determine if application of bone morphogenic protein 7 (BMP-7) promotes physiological bone healing of non-unions and to investigate if serum cytokine analysis may serve as a promising tool in the analysis of adjunct non-union therapy. Therefore we analyzed the influence of BMP-7 application on the serum cytokine expression patterns on patients with impaired bone healing compared to patients that showed proper bone healing.
\end{abstract}

Methods: Our study involved analyzing blood samples from 208 patients with long bone fractures together with patients that subsequently developed non-unions. From this large pool, 15 patients with atrophic non-union were matched to 15 patients with atrophic non-union treated with local application of BMP-7 as well as normal bone healing. Changes in the cytokine expression patterns were monitored during the 1st, 2nd, 4th, 8th, 12th and 52nd week. The patients were followed both clinically and radiologically for the entire duration of the study. Serum cytokine expression levels of transforming growth factor beta (TGF- $\beta$ ), platelet-derived growth factor (PDGF) and basic fibroblast growth factor (bFGF) were analyzed and compared.

Results: Serum expression of TGF- $\beta$ were nearly parallel in all three groups, however serum concentrations were significantly higher in patients with proper bone healing and those treated with BMP-7 than in patients with non-unions $(p<0.05)$. bFGF serum concentrations increased initially in patients with proper bone healing and in those treated with BMP-7. Afterwards, values decreased; bFGF serum concentrations in the BMP-7 group were significantly higher than in the other groups $(p<0.05)$. PDGF serum concentration levels were nearly parallel in all groups, serum concentrations were significantly higher in patients with proper bone healing and those treated with BMP-7 than in patients with non-unions $(p<0.05)$.

(Continued on next page)

\footnotetext{
* Correspondence: arashmoghaddam@web.de

${ }^{1}$ HTRG - Heidelberg Trauma Research Group, Trauma and Reconstructive

Surgery, Center of Orthopaedics, Traumatology and Paraplegiology,

Heidelberg University Hospital, Schlierbacher Landstraße 200a, D-69118

Heidelberg, Germany

Full list of author information is available at the end of the article
} 
(Continued from previous page)

Conclusion: Treatment with BMP-7 in patients with former non-unions led to similar cytokine expression patterns after treatment as those found in patients with proper bone healing. Our results suggest that treatment with BMP-7 promote healing of non-unions. Furthermore, quantitative measurement of serum cytokine expression is a promising tool for evaluating the effectiveness of additional non-union therapies such as adjunct application of growth factors.

Keywords: Non-union, Cytokines, BMP-7, Fracture healing, Pseudarthrosis, TGF- $\beta$, PDGF, bFGF

\section{Background}

The therapy of non-unions in trauma surgery still remains a challenge [1]. Currently there are various surgical treatment options for non-unions [2], including revision surgery, medullary reaming, and dynamisation of nails. The gold standard for treating non-unions is the use of autologous bone grafts [3] harvested from the iliac crest, which have osteogenic, osteoinductive, and osteoconductive properties [4,5]. Patients who do not respond to such therapies require further surgical interventions, such as adjunct application of bone morphogenic protein 7 (BMP-7) during revision surgery.

In the last 20 years, various attempts have been made to develop treatment plans involving growth factors for non-unions. BMP-7, a member of the transforming growth factor beta (TGF- $\beta$ ) - superfamily, is one of the first growth factors that was approved for clinical use. Originally applied for non-unions of the tibia, it has been used on many localizations for over 10 years without significant complications [6]. In clinical studies, BMP-7 was documented as being 80-90\% effective in healing non-unions, showing comparable or even better results as autologous bone grafting $[7,8]$.

Despite its potential for therapy, the success of BMP-7 on fracture healing has only been confirmed through radiological and clinical parameters in humans. A major disadvantage of these methods is that evaluation of fracture healing is only possible after at least 3 months [9], and the frequency of $x$-ray and CT imaging is limited due to radiation exposure. Studies on the modulating effects of BMP-7 on serum cytokine levels in animals are limited in their transferability to humans [10].

In this clinical study, we analyzed the effects of BMP-7 application during non-union therapy on human serum cytokine levels during a 1 year follow-up study. The basis for our research concept came from previous studies, in which we described several cytokine expression patterns in regular and failed bone healing [11-14]. We were able to detect significant differences in expression patterns at certain time points, which suggested that fracture healing was delayed or failed. In a further study we could show that smoking decreased the expression of TGF- $\beta$ in patients after surgery [15]. From these studies we concluded that measuring serum cytokine expression is a valid instrument for evaluating bone healing [15, 16]. We chose to use this concept in order to investigate if treatment with BMP-7 may promote physiological healing of non-unions and if quantitative measurement of serum cytokine expression is a promising tool in the future for evaluating the effectiveness of additional non-union therapies such as adjunct application of growth factors.

\section{Methods}

\section{Patient recruitment, clinical investigation}

Two hundred and eight Patients (159 men, 49 women, aged 18 to 76 years) were enrolled in our study at BG Trauma center Ludwigshafen between 2002 and 2007. Inclusion criteria were diaphyseal fractures of long bones (humerus, radius, ulna, femur, tibia). Exclusion criteria were the existence of systemic diseases such as hypo- or hyperthyroidism, diabetes mellitus, advanced liver disease, chronic inflammatory diseases, malignancy, and extreme obesity as well as long-term use of immunosuppressive drugs, which can influence normal cytokine levels. All enrolled patients were invited to attend follow-up examinations at standardized intervals: 1, 2, 4, 8, 12 weeks and 1 year after surgery. Blood samples were taken at every follow-up examination. Patients with radiological and clinical evidence of failed fracture healing and formation of a non-union underwent revision surgery involving debridement, BMP-7 application, and re-osteosynthesis. In these cases, blood samples were taken until definitive healing of the fracture could be confirmed.

Of the 208 patients, 160 showed proper bone healing according to $\mathrm{x}$-ray results, clinical stability, and pain-free weight-bearing; 48 patients suffered from non-unions, from which 13 patients received treatment with BMP-7. Furthermore, 18 patients were treated with BMP-7 in our hospital after failed primary treatment elsewhere. We included these patients in the follow-up schedule mentioned above. The study was conducted in accordance with the declaration of Helsinki and after the approval of the ethics committee of the Ruprechts-Karls-University of Heidelberg (nr. 157/2002). 


\section{Matching}

We compared three groups of patients:

1. Fracture patients developing non-unions

2. Non-union patients treated with BMP-7

3. Fracture patients with proper healing

Patients with fractures that failed to heal after primary treatment were assigned to the non-union group. After treatment with BMP-7, these Patients were assigned to the BMP-7 group. In two cases, this was not possible, so we matched two patients with two BMP-7 patients. We matched the two groups with a third group of patients with proper fracture healing. Patients were matched on the basis of five criteria: age (+/ -5 years), sex, localization of fracture, type of fracture (classification by the "Association for the Study of Internal Fixation" (AO/ ASIF)) and type of osteosynthesis. If more than one match was found for a non-union patient, than the patient with the most similar type of fracture was chosen. According to matching criteria three groups ( $n$ =15) could be formed of the above mentioned total study patients, whereby patients that developed a nonunion and subsequently were treated with BMP-7 were assigned to two groups (Table 1).

\section{Administration of BMP-7}

Patients that showed radiological and clinical evidence of failed fracture healing and formation of a non-union during the follow-up examinations subsequently underwent revision surgery. In particular revision surgery included radical debridement and resection of avital bone tissue and furthermore re-osteosynthesis was performed, providing a better biomechanical stability. Hereafter the defect site was filled with autologous bone marrow that has an osteogenic potential, thus able of forming bone independently [17]. To maximize the effect the autologous bone marrow was enhanced by a nonrecurring local application of $3.3 \mathrm{mg}$ BMP-7 [18-21].

\section{Sample acquisition and measuring of serum cytokines}

Venous blood samples from all patients were collected during follow-ups. Samples were drawn between 8 a.m. and 11 a.m. on an empty stomach. Serum was separated, and stored at-80 ${ }^{\circ} \mathrm{C}$. Serum samples were thawed and equilibrated to room temperature for at least $2 \mathrm{~h}$ before analysis. Measurement was set in duplicates. Serum levels of TGF- $\beta-1$, PDGF and bFGF were measured with commercially available ELISA kits ('Quantikine ${ }^{\circ} E L I S A$ Kits'; R\&D Systems, Minneapolis, MN, USA). Assays were conducted according to the manufacturer's instructions. Levels measured 1 year after trauma defined baseline levels in the union group, whereas levels measured 1 year after failed bone healing respectively revision surgery were defined baseline in the non-union group respectively BMP-7 group.

\section{Statistics}

Pretrial power analysis revealed a minimum size of nine patients in each group. Serum levels are expressed as mean absolute concentrations \pm standard error of the mean (SEM) per time point and group. The 1 year follow-up serum levels were determined as base levels in order to facilitate analysis of our data. The Friedmantest was applied to detect significant changes over time during the entire investigative period. If significant, the Wilcoxon signed rank test for paired samples was used to recognize significant changes between the reference values and post-traumatic results within both groups. For statistical comparison of serum values at a certain time point between groups, the Wilcoxon signed rank test for paired samples was used. The confidence limit was predetermined at a level of 0.05 . Statistical analysis was carried out by use of SPSS for Windows 11.0 (Norusis SPSS GmbH Inc.).

\section{Results}

\section{TGF- $\beta$}

Generally speaking, TGF- $\beta$ serum concentrations increased in all groups during the first 2 weeks after surgery (BMP-7 week 1: $53.80 \pm 3.63 \mathrm{ng} / \mathrm{ml}$, week 2: $67.94 \pm 2.32 \mathrm{ng} / \mathrm{ml}$; Non-union week 1: $47.90 \pm$ $3.29 \mathrm{ng} / \mathrm{ml}$. week 2: $58.63 \pm 2.94 \mathrm{ng} / \mathrm{ml}$; Union week 1: $57.32 \pm 4.85 \mathrm{ng} / \mathrm{ml}$. week 2: $62.98 \pm 4.59 \mathrm{ng} / \mathrm{ml})$, decreased after the 2nd week (BMP-7 week 4: $56.98 \pm$ $2.29 \mathrm{ng} / \mathrm{ml}$, Non-union week 4: $43.64 \pm 1.90 \mathrm{ng} / \mathrm{ml}$, Union week 4: $61.75 \pm 4.02 \mathrm{ng} / \mathrm{ml}$ ), and plateaued after the 6th week (BMP-7 week 6: $54.36 \pm 2.13 \mathrm{ng} / \mathrm{ml}$,

Table 1 Patient demographics and clinical characteristics

\begin{tabular}{|c|c|c|c|c|c|c|c|c|c|c|c|c|c|c|c|}
\hline \multirow[b]{2}{*}{ Patients } & \multirow[b]{2}{*}{$N$} & \multicolumn{2}{|c|}{ Gender } & \multirow[t]{2}{*}{ Age } & \multicolumn{4}{|c|}{ Type of Fracture (AO) } & \multicolumn{4}{|c|}{ Lokalisation of Fracture } & \multicolumn{3}{|c|}{ Fixation } \\
\hline & & $q$ & $\pi$ & & $A$ & $B$ & C & $\mathrm{C} 1^{\circ}$ & Femur & Tibia & Forearm & Upper arm & Nail & Plate & Ext. Fix. \\
\hline All patients & 45 & 9 & 36 & $47,37 \pm 11,54$ & 30 & 12 & 15 & 9 & 12 & 48 & 3 & 3 & 27 & 36 & 3 \\
\hline Union group & 15 & 3 & 12 & $47,2 \pm 12,00$ & 10 & 4 & 5 & 3 & 4 & 16 & 1 & 1 & 9 & 12 & 1 \\
\hline Non-union group & 15 & 3 & 12 & $47,53 \pm 11,48$ & 10 & 4 & 5 & 3 & 4 & 16 & 1 & 1 & 9 & 12 & 1 \\
\hline BMP-7 group & 15 & 3 & 12 & $47,53 \pm 11,48$ & 10 & 4 & 5 & 3 & 4 & 16 & 1 & 1 & 9 & 12 & 1 \\
\hline
\end{tabular}

Abbreviations: BMP-7 Bone morphogenic protein 7; Ext. Fix. Osteosynthesis by external fixation; AO AO-Classification. Age is expressed as mean years \pm SD 
Non-union week 6: $45.90 \pm 2.79 \mathrm{ng} / \mathrm{ml}$, Union week 6: $50.72 \pm 2.58 \mathrm{ng} / \mathrm{ml}$ ). Serum concentrations were higher in patients with proper bone healing and those treated with BMP-7 than in patients with non-unions (Fig. 1). Patients with non-unions showed a decrease below base levels (Base level Non-union: $50.64 \pm 2.67 \mathrm{ng} / \mathrm{ml}$ ) after the second week. Patients who received treatment with BMP-7 and patients with proper bone healing showed less decrease in serum concentrations after the second week and concentrations remained above base levels (Base level BMP-7: $51.39 \pm 2.95 \mathrm{ng} /$ $\mathrm{ml}$ and Union: $48.75 \pm 2.82 \mathrm{ng} / \mathrm{ml}$ ). Differences between the union and non-union group were significant in the 4th week $(p=0.00)$ while differences between the non-union and the BMP-7 group were significant in the 2nd, 4th, 8th, and 12th week $(p=0.031 ; p=0.00$; $p=0.048 ; p=0.026$ ).

\section{PDGF}

PDGF serum concentration levels were nearly parallel in all three groups (Fig. 2). Values increased between the first and the second week (BMP-7 week 1: $23.25 \pm$ $2.45 \mathrm{ng} / \mathrm{ml}$, week 2: $29.23 \pm 3.16 \mathrm{ng} / \mathrm{ml}$; Non-union week 1: $20.75 \pm 2.19 \mathrm{ng} / \mathrm{ml}$, week $2: 26.66 \pm 2.50 \mathrm{ng} / \mathrm{ml}$; Union week 1: $24.78 \pm 1.50 \mathrm{ng} / \mathrm{ml}$, week $2: 30.38 \pm$ $1.66 \mathrm{ng} / \mathrm{ml}$ ) and decreased afterwards (BMP-7 week 8: $25.35 \pm 1.65 \mathrm{ng} / \mathrm{ml}$, Non-union week 8: $21.82 \pm$ $1.75 \mathrm{ng} / \mathrm{ml}$, Union week 8: $25.07 \pm 1.78 \mathrm{ng} / \mathrm{ml})$. Serum

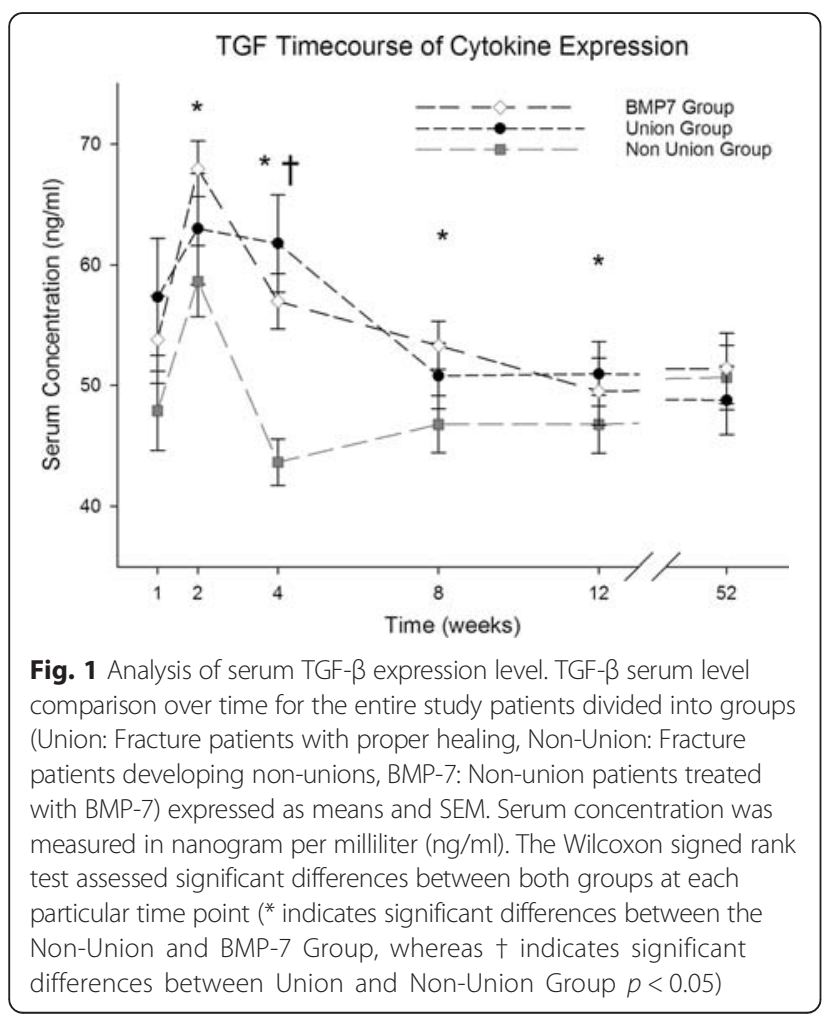

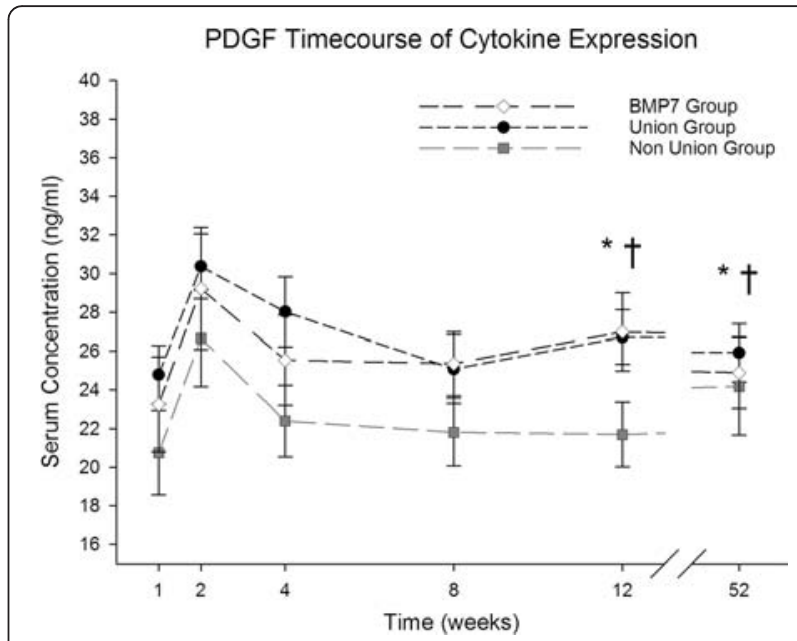

Fig. 2 Analysis of serum PDGF expression level. PDGF serum level comparison over time for the entire study patients divided into groups (Union: Fracture patients with proper healing, Non-Union: Fracture patients developing non-unions, BMP-7: Non-union patients treated with BMP-7) expressed as means and SEM. Serum concentration was measured in nanogram per milliliter $(\mathrm{ng} / \mathrm{ml})$. The Wilcoxon signed rank test assessed significant differences between both groups at each particular time point (* indicates significant differences between the Non-Union and BMP-7 Group, whereas $†$ indicates significant differences between Union and Non-Union Group $p<0.05$ )

concentrations in non-union patients were lower than those in the other groups during the whole study, declining below the base value (Base level Non-union: $24.18 \pm 2.51 \mathrm{ng} / \mathrm{ml}$ ) after the second week without reaching this value during the following course. In the union and the BMP-7 group, values increased slightly after week 8 , and differences in PDGF serum concentration between the union and the non-union groups as well as between the non-union and the BMP-7groups were significant after week 12 (BMP-7 week 12: $26.99 \pm 2.04 \mathrm{ng} / \mathrm{ml}$, Non-union week 12: $21.70 \pm$ $1.67 \mathrm{ng} / \mathrm{ml}$, Union week $12: 26.73 \pm 1.41 \mathrm{ng} / \mathrm{ml} ; p=$ 0.033 and $p=0.041$ respectively).

\section{bFGF}

bFGF serum concentrations increased in between the first and the second week in patients with proper bone healing and in those treated with BMP-7 (BMP-7 week 1: $7.96 \pm 2.03 \mathrm{ng} / \mathrm{ml}$, week $2: 36.77 \pm 10.12 \mathrm{ng} / \mathrm{ml}$; Nonunion week 1: $5.94 \pm 1.59 \mathrm{ng} / \mathrm{ml}$, week $2: 6.60 \pm 1.08 \mathrm{ng} /$ $\mathrm{ml}$; Union week 1: $5.09 \pm 1.03 \mathrm{ng} / \mathrm{ml}$, week 2: $13.12 \pm$ $1.92 \mathrm{ng} / \mathrm{ml}$ ) (Fig. 3). Afterwards, values decreased (BMP7 week 4: $27.48 \pm 9.23 \mathrm{ng} / \mathrm{ml}$, Non-union week 4: $6.85 \pm$ $1.18 \mathrm{ng} / \mathrm{ml}$, Union week 4: $6.05 \pm 1.19 \mathrm{ng} / \mathrm{ml}$ ). Over the whole investigation period, bFGF serum concentrations in the BMP-7 group were higher than in the other groups. In non-union patients, values did not change significantly during the whole course but varied around 


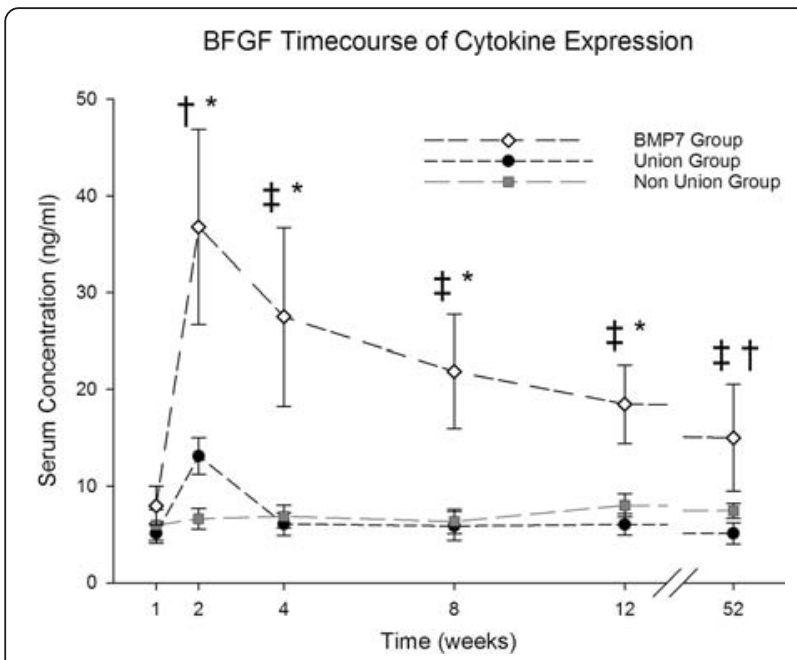

Fig. 3 Analysis of serum BFGF expression level. BFGF serum level comparison over time for the entire study patients divided into groups (Union: Fracture patients with proper healing, Non-Union: Fracture patients developing non-unions, BMP-7: Non-union patients treated with BMP-7) expressed as means and SEM. Serum concentration was measured in nanogram per milliliter (ng/ml). The Wilcoxon signed rank test assessed significant differences between both groups at each particular time point ( $\uparrow$ indicates significant differences between the Non-Union and Union Group, * indicates significant differences between the Non-Union and BMP-7 Group, whereas ₹ indicates significant differences between Union and BMP-7 Group $p<0.05$ )

the base level. Differences between the union and the non-union group were significant in the second week and at base levels (Base level BMP-7: $15.01 \pm 5.53 \mathrm{ng} / \mathrm{ml}$, Non-union: $7.43 \pm 0.77 \mathrm{ng} / \mathrm{ml}$, Union: $5.09 \pm 1.12 \mathrm{ng} / \mathrm{ml}$; $p<0.05)$. Differences between the BMP-7 and the nonunion group were significant at week $2,4,8$ and 12 (BMP-7 week 8: $21.86 \pm 5.90 \mathrm{ng} / \mathrm{ml}$, week 12: $18.48 \pm$ $4.07 \mathrm{ng} / \mathrm{ml}$; Non-union week 8: $6.32 \pm 1.27 \mathrm{ng} / \mathrm{ml}$, week 12: $7.99 \pm 1.21 \mathrm{ng} / \mathrm{ml}$; Union week $8: 5.85 \pm 1.49 \mathrm{ng} / \mathrm{ml}$, week 12: $6.01 \pm 1.11 \mathrm{ng} / \mathrm{ml})(p=0.003 ; p=0.011 ; p=$ $0.011 ; p=0.014)$, differences between the BMP-7 and the union group were significant at week 4, 8, 12 and at base levels $(p=0.004 ; p=0.002 ; p=0.001 ; p=0.026)$.

Serum concentrations corresponded with previous results in other studies [22-24]. Differences in serum concentrations of TGF- $\beta$, PDGF, and bFGF were significant between patients with proper bone healing and nonunion patients. Results showed that the application of BMP-7 lead to expression patterns similar to those in patients with proper fracture healing. Interestingly, bFGF increased to a much higher level after week 2 in the BMP-7 group compared to other groups. Generally speaking, TGF $\beta$, PDGF and bFGF concentrations peaked after week 2 and decreased afterwards, and were lower in patients with non-unions.

\section{Discussion}

In this prospective, controlled clinical study, we analyzed the serum concentrations of TGF- $\beta$, PDGF and bFGF during a 1 year follow-up in non-union patients treated with BMP-7 and compared them to the cytokine expression pattern of patients with failed as well as with physiological bone healing to determine whether the local application of BMP-7 modulates the microenvironment in the fracture gap and thereby influences secondary bone regeneration.

\section{TGF-ß}

Recent studies in fracture healing showed that successful fracture healing is a complex process involving the growth and differentiation of mesenchymal stem cells, regulation of cytokines (inflammatory and osteogenic) and the resorption of extracellular matrix [25]. The golden standard in non-union therapy is the transplantation of autologous bone graft [26-29], more recently this therapy was combined with the application of BMP7 and studies show a better outcome after non-union treatment if BMP-7 was applied [18, 30, 31]. The underlying mechanism of the clinical success of BMP-7 application remains uncertain. In the current study we sought to determine the influence of local BMP-7 application on successful bone healing utilizing quantitative serum measurement of osteogenic cytokine expression pattern. Transforming growth factor beta is initially secreted from thrombocytes in areas of hematoma after injury, but later from chondrocytes and osteoblasts during fracture healing. It stimulates the proliferation of different cells including osteoblasts, chrondroblasts, and chondrocytes [22, 23]. Regarding the serum concentration of TGF- $\beta$ our results showed that patients in the BMP-7 group had lower levels after the first week compared to the group with physiological bone healing suggesting that osseous biology was still impaired at this time. However local application of BMP-7 lead to an increase in TGF- $\beta$ after the second week that lasted longer than in every other group. It has been shown that the concentrations of bone morphogenic proteins were decreased in patients suffering from non-union, thereby indicating that a down-regulation in expression of osteogenic BMPs might be responsible for failed fracture healing $[32,33]$. In our study patients with failed fracture healing were treated with adjunct application of BMP-7 serving as a substitution of known lower BMP concentrations in patients with failed fracture healing, thereby modulating the microenviroment in the fracture gap and increasing local concentration of BMP-7. BMPs and TGF- $\beta$ are both members of TGF- $\beta$ protein superfamily and promote bone formation. The most important effect of TGF- $ß$ is the stimulation of the synthesis of components of the extracellular matrix (e.g. collagen I and III). 
This has been shown to be pivotal in the early stages of bone healing as scaffolding for later bone mineralization [34]. BMPs facilitate osteogenic differentiation due to various pathways in order to achieve successful bone healing [34]. Peak concentrations in the BMP-7 group were measured after week 4, suggesting that BMP-7 was able to stimulate osteoblast biology and lead to higher expression of TGF- $\beta$. BMP-7 appears to have its most significant impact between week 2 and 4 [35]. A steeper decrease in the non-union group between week 2 and 4 compared to other groups could be attributed to a decrease in hard callus formation, which plays a crucial role in non-union formation. In our previous publications, we attributed this decrease to hard callus formation between week 2 and 4 and proposed this phase to be crucial in nonunion formation. It is known that TGF- $\beta$ plays an important role in the formation of cartilage-like tissue, whereas a decrease in the expression of TGF- $\beta$ accounts for an impaired potential in the formation of cartilage-like tissue. Hereby indicating that impaired expression of TGF- $\beta$, as seen in decreased plasma levels, may provide a predisposing factor of an dysfunctional cartilage and osseous regeneration [24].

In conclusion it is known that local and systemic concentrations of different osteogenic cytokines increase during physiological fracture healing, in particular sufficient serum concentrations of TGF- $\beta$ have been shown to be pivotal to fracture healing [36]. It has been reported that TGF- $\beta$ and BMPs are capable of inducing each others expressions [33, 34], however patients with failed bone healing are known to have impaired local BMP concentration, furthermore the current study showed that the concentration of TGF- $B$ in concerned patients is decreased during the initial 12 months; indicating that BMP-7 and TGF- $\beta$ have to be present in fracture healing in a sufficient concentration [37]. Our results show that local application of BMP-7 serves as a substitution of impaired BMP-7 levels in non-union patients and thereby modulating the microenviroment in the fracture gap and promoting bone regeneration. The results of our current study accentuate the findings of previous studies indicating that lower circulating levels of TGF- $\beta$ could be utilized as a predictor of delayed bone healing and non-union [11].

\section{PDGF}

Platelet derived growth factor was first discovered in thrombocytes, but was later found in granulation tissue, hypertrophic chondrocytes, osteoblasts, and osteoclasts during bone healing. PDGF has got many effects on fracture healing: it releases mesenchymal stem cells from blood vessels and is a potent mitogen for mesenchymal stem cells (MSC) [38, 39]. It also promotes angiogenesis by increasing the secretion of vascular endothelial growth factor (VEGF) [12, 40]. PDGF deficiency may lead to impaired bone healing as shown in diabetic animals [41]. After PDGF application in osteoporotic animals, improvement was seen in bone healing. Furthermore, PDGF application improved bone healing in diabetic patients [40], more recently published data indicates promising results in the treatment of osteochondral defects of the talus, hereby application of PDGF provides a benefit in bone healing [42].

Our findings on PDGF concentration levels in the union and the non-union group are supported by previous studies [12]. Union patients had higher levels at all time points than non-union patients. Levels increased in both groups after surgery, peaked after the fourth week, and decreased thereafter. Similar to TGF- $\beta$, levels decreased steeper in non-union-patients as in other groups. We explained this by hard callus formation as explained above. This would be supported by previous research showing that PDGF application led to an increase in callus density and volume in animal models [43]. Patients treated with BMP-7 had higher levels of PDGF than non-union patients; which is possibly due to increased PDGF secretion from BMP-7 stimulation. There was an increase in the union and the BMP-7 group between week 8 and 12, which was not detected in non-union patients. This phase of bone healing is associated with remodeling, which could be influenced by PDGF. Non-unions may not have reached the remodeling phase, resulting in reduced cytokine levels. In conclusion local application of BMP-7 increases PDGF level to a physiological extent, thereby BMP-7 substitution enhances mitogenesis of MSCs in the initial phase of bone healing, concluding in a possibly higher concentration of MSC in the fracture gap leading to favorable fracture healing. Furthermore BMP-7 application leads to an increased angiogenesis in the initial phase of fracture healing by an enhanced expression of PDGF and bFGF. The results of our study indicate that application of BMP-7 improves bone healing by enhanced angiogenesis, mitogenesis and osteogenesis.

\section{bFGF}

Angiogenic growth factors are mainly expressed during the early phases of fracture healing whereas osteogenic growth factors are continuously expressed during bone healing and remodeling [44]. Basic fibroblast growth factor plays an important role in the angiogenic response after fracture healing [45], as well as in general bone healing $[46,47]$. Apparently due to complex processes: bFGF abrogated the bone stimulating effects of BMP-7 in vitro $[48,49]$, and reversibly inhibited osteogenesis in human adipose-tissue derived stromal cells [50]. BFGF 
retains MSCs in a more "immature" state and MSC lines responding to bFGF stimulation secrete factors which provided an environment for the first stage of fracture repair [51]. Consequently, one putative function of bFGF could be the retention of mesenchymal stem cells during the first phases of fracture healing before ossification takes place. Up to date multiple combination of osteogenic and angiogenic growth factors has been used and studied in combination, however the combination of BMPs and bFGF have been one of the most popular growth factors used $[52,53]$. Regarding the effect of the combined application of BMP and BFGF contradictory conclusions have been found, in particular studies have shown stimulatory and inhibitory effects [44]. In the present study, bFGF levels did not alter in non-unions while significant increases in the union groups were observed after the second week. This suggests that bFGF plays a crucial role during the first stages of fracture repair possibly as an angiogenic growth factor. BMP-7 application led to an enormous increase in bFGF expression and concentrations remained significantly higher even 1 year after surgery. In particular BMP-7 application lead to an enormous increase in the initial phase of bone healing, indicating that BMP-7 application leads to an enhanced angiogenesis in the early stages of bone healing by increasing local bFGF concentrations, furthermore bFGF levels were increased during the whole period of time, thereby promoting bone healing by a supplementary osteogenic effect during initial bone healing and later remodeling. In conclusion the results of our study accentuate a favorable effect of increased local bFGF and BMP-7 concentrations on bone healing; either due to direct stimulation of angiogenesis and osteogenesis due to BMP-7 application evaluated by increased bFGF serum level or due to an initial stimulation of bFGF expression and subsequently a co-stimulatory effect of increased local BMP-7 and bFGF concentrations. These findings stress the significance of a molecular link between BMP and bFGF signal pathways [54].

\section{Limitations}

Non-unions are a severe but an infrequent complication resulting in clinical studies concerning non-union therapy being complex and it explains the small size of our patient collective. Despite a large patient collective just a small number of patients could be included in the study due to our strict inclusion and exclusion criteria. In the context of current literature and our recent studies $[14,55]$, our patient collective size is still sufficient. Another limitation of this study may arise from the different age of samples, samples were collected throughout the whole study period, however measurements were performed cumulated for all samples, which could influence the cytokine concentration.
However, since samples of all groups were concerned equally we believe that the sample age does not interfering with the results of our study. The strengths of this study are its prospective approach, the clear inclusion and exclusion criteria, and the matching of patients. This allowed us to eliminate factors that could bias the evaluation of these patient groups.

\section{Conclusions}

In this prospective, controlled study, we analyzed the serum concentrations of TGF- $\beta$, PDGF and bFGF during a 1 year follow-up in non-union patients treated with BMP-7. We compared them to the cytokine expression pattern of patients with failed and with proper bone healing to determine if the local application of BMP-7 modulates the microenvironment in the fracture gap and thereby influences secondary bone regeneration. The results of our study show that local application of BMP-7 lead to a cytokine expression pattern of bone healing associated cytokines (TGF $\beta$, PDGF and bFGF) that resembled the expression patterns of patients with proper bone healing and differed significantly from those in patients developing non-unions. Concluding in the current study we could show that patients that develop non-unions have an abnormal cytokine expression pattern of osteogenic cytokines, in particular serum cytokine levels were decreased beginning at the start of fracture healing. Local application of BMP-7 elevated serum cytokine level to a physiological extent and thereby facilitated bone regeneration by enhanced angiogenesis, mitogenesis and osteogenesis. We believe our study adds important knowledge to the literature in the field by providing a possible mechanism of how adjunct application of BMP-7 promotes bone healing gathered from clinical data.

Furthermore this present study showed that quantitative measurement of serum cytokine expression is a valid instrument in evaluating the biological impact of BMP-7 and thus the value of possible non-union therapies. Further studies using this protocol to determine serum cytokine expression levels will help elucidate the effectiveness of other non-union therapies, and compare these therapies in order to make a biology-based decision for the treatment of non-unions.

\section{Ethics, consent and permission}

Patients were included in our study after giving a full written declaration of consent, including the use of the gathered data, as well as the consent to publish the data acquired. The study was conducted in accordance with the declaration of Helsinki and after the approval of the ethics committee of the Ruprechts-Karls-University of Heidelberg (nr. 157/2002). 


\section{Abbreviations}

BMP-7: Bone morphogenic protein 7; BMP: Bone morphogenic protein: TGF- $\beta$ : Transforming growth factor beta; PDGF: Platelet-derived growth factor; BFGF: Basic fibroblast growth factor; AO/ASIF: Association for the study of internal fixation; SEM: Standard error of the mean;

MSC: Mesenchymal stem cell; VEGF: Vascular endothelial growth factor.

\section{Competing interest}

The authors declare that they have no competing interests.

\section{Authors' contribution}

AM has finalized the design of the study, managed and performed the sample acquisition and has helped in interpretation of the data as well as revising the manuscript. LB has performed the serum cytokine expression analysis and helped to draft the manuscript. PH has helped in interpretation of the data as well as helped to draft the manuscript and revised it critically for important intellectual content. DB participated in the design of the study and helped in performing the statistical analysis. BB has helped in interpretation of the data and revised the manuscript. AW participated in the design of the study. GZ participated in the design and coordination of the study, helped in the interpretation of data and helped to draft and revise the manuscript. All authors read and approved the final manuscript.

\section{Authors' information}

AM: consultant for orthopaedic surgery and trauma surgery at the University Hospital Heidelberg. LB: resident for orthopaedic surgery and trauma surgery at the St. Marienkrankenhaus. PH: resident for orthopaedic surgery and trauma surgery at the University Hospital Heidelberg. DB: resident for anesthesiology at the Hospital Frankenthal. BB: head of the Department for paraplegiology and technical orthopaedics at the BG Trauma Center. AW: former director of BG Trauma Center. GZ: head of the department for trauma surgery at the Theresienkrankenhaus and St. Hedwigs-Klinik GmbH.

\section{Acknowledgements}

We acknowledge the financial support of the Deutsche Forschungsgemeinschaft and Ruprecht-Karls-Universität Heidelberg within the funding program Open Access Publishing.

\section{Author details}

'HTRG - Heidelberg Trauma Research Group, Trauma and Reconstructive Surgery, Center of Orthopaedics, Traumatology and Paraplegiology, Heidelberg University Hospital, Schlierbacher Landstraße 200a, D-69118 Heidelberg, Germany. ${ }^{2}$ Department of Orthopaedics and Traumatology, St. Marienkrankenhaus, Salzburger Str. 15, 67067 Ludwigshafen, Germany. ${ }^{3}$ Department for anesthesiology, Stadtklinik Frankenthal, Elsa-Brändenström Str. 1, D-67227 Frankenthal, Germany. ${ }^{4}$ Berufsgenossenschaftliche Unfallklinik Ludwigshafen, Department of Paraplegiology, Ludwig-Guttmann-Straße-13, D-67071 Ludwigshafen, Germany. ${ }^{5}$ Berufsgenossenschaftliche Unfallklinik Ludwigshafen, Trauma Center, Ludwig-Guttmann-Straße-13, D-67071 Ludwigshafen, Germany. ${ }^{6}$ Department for Trauma Surgery, Theresienkrankenhaus und St. Hedwigs-Klinik GmbH, Bassermannstr. 1, D-68165 Mannheim, Germany.

Received: 19 June 2015 Accepted: 19 January 2016

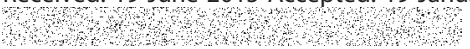

\section{References}

1. Schmidmaier G, Moghaddam A. Long bone nonunion. Z Orthop Unfall. 2015;153(6):659-76. doi:10.1055/s-0035-1558259.

2. Rodriguez-Merchan EC, Forriol F. Nonunion: general principles and experimental data. Clin Orthop Relat Res. 2004;419:4-12.

3. Myeroff $C$, Archdeacon M. Autogenous bone graft: donor sites and techniques. J Bone Joint Surg Am. 2011;93(23):2227-36. doi:10.2106/JBJS.J.01513.

4. Janicki P, Schmidmaier $G$. What should be the characteristics of the ideal bone graft substitute? Combining scaffolds with growth factors and/or stem cells. Injury. 2011;42 Suppl 2:S77-81. doi:10.1016/j.injury.2011.06.014.

5. Giannoudis PV, Dinopoulos H, Tsiridis E. Bone substitutes: an update. Injury. 2005;36 Suppl 3:S20-7. doi:10.1016/j.injury.2005.07.029.
6. Shah P, Keppler L, Rutkowski J. Bone morphogenic protein: an elixir for bone grafting-a review. Eur J Oral Implantol. 2012;38(6):767-78. doi:10.1563/ AAID-JOI-D-10-00196.

7. Garrison KR, Shemilt I, Donell S, Ryder JJ, Mugford M, Harvey I, et al. Bone morphogenetic protein (BMP) for fracture healing in adults. Cochrane Database Syst Rev. 2010;6:CD006950. doi:10.1002/14651858.CD006950.pub2.

8. TRACP. 5b and CTX as osteological markers of delayed fracture healing. 2010.

9. Bishop JA, Palanca AA, Bellino MJ, Lowenberg DW. Assessment of compromised fracture healing. J Am Acad Orthop Surg. 2012;20(5):273-82. doi:10.5435/JAAOS-20-05-273.

10. den Boer FC, Wippermann BW, Blokhuis TJ, Patka P, Bakker FC, Haarman HJ. Healing of segmental bone defects with granular porous hydroxyapatite augmented with recombinant human osteogenic protein-1 or autologous bone marrow. J Orthop Res. 2003;21(3):521-8. doi:10.1016/S07360266(02)00205-X

11. Zimmermann G, Henle P, Kusswetter M, Moghaddam A, Wentzensen A, Richter W, et al. TGF-beta1 as a marker of delayed fracture healing. Bone. 2005;36(5):779-85. doi:10.1016/j.bone.2005.02.011.

12. Weiss S, Henle P, Bidlingmaier M, Moghaddam A, Kasten P, Zimmermann G. Systemic response of the GH/GF-I axis in timely versus delayed fracture healing. Growth Horm IGF Res. 2008;18(3):205-12. doi:10.1016/j.ghir.2007.09.002.

13. Weiss S, Zimmermann G, Pufe T, Varoga D, Henle P. The systemic angiogenic response during bone healing. Arch Orthop Trauma Surg. 2009: 129(7):989-97. doi:10.1007/s00402-008-0777-5.

14. Moghaddam A, Muller U, Roth HJ, Wentzensen A, Grutzner PA, Zimmermann G. TRACP 5b and CTX as osteological markers of delayed fracture healing. Injury. 2011;42(8):758-64. doi:10.1016/j.injury.2010.11.017.

15. Moghaddam A, Weiss S, Wolf CG, Schmeckenbecher K, Wentzensen A, Grutzner PA, et al. Cigarette smoking decreases TGF-b1 serum concentrations after long bone fracture. Injury. 2010;41(10):1020-5. doi:10.1016/j.injury.2010.03.014.

16. Moghaddam A1, Weiss S, Wölfl CG, Schmeckenbecher K, Wentzensen A, Grützner PA, et al. Cigarette smoking decreases TGF- $\beta 1$ serum concentrations after long bone fracture, (2010).

17. Bosemark P, Perdikouri C, Pelkonen M, Isaksson H, Tagil M. The masquelet induced membrane technique with BMP and a synthetic scaffold can heal a rat femoral critical size defect. J Orthop Res. 2015; 33(4):488-95. doi:10.1002/jor.22815.

18. Moghaddam-Alvandi A, Zimmermann G, Buchler A, Elleser C, Biglari B, Grutzner PA, et al. Results of nonunion treatment with bone morphogenetic protein 7 (BMP-7). Unfallchirurg. 2012;115(6):518-26. doi:10. 1007/s00113-011-2100-0

19. Karger C, Kishi T, Schneider L, Fitoussi F, Masquelet AC. Treatment of posttraumatic bone defects by the induced membrane technique. Orthop Traumatol Surg Res. 2012;98(1):97-102. doi:10.1016/j.otsr.2011.11.001.

20. Pelissier P, Masquelet AC, Bareille R, Pelissier SM, Amedee J. Induced membranes secrete growth factors including vascular and osteoinductive factors and could stimulate bone regeneration. J Orthop Res. 2004;22(1):739. doi:10.1016/50736-0266(03)00165-7.

21. Masquelet AC, Begue T. The concept of induced membrane for reconstruction of long bone defects. The Orthopedic clinics of North America. 2010:41(1):27-37; table of contents. doi:10.1016/j.ocl.2009.07.011.

22. Lind M. Growth factor stimulation of bone healing. Effects on osteoblasts, osteomies, and implants fixation. Acta Orthop Scand Suppl. 1998;283:2-37.

23. Patil $A S$, Sable RB, Kothari RM. An update on transforming growth factor-beta (TGF-beta): sources, types, functions and clinical applicability for cartilage/bone healing. J Cell Physiol. 2011;226(12):3094-103. doi:10. 1002/jcp.22698.

24. Tekari A, Luginbuehl R, Hofstetter W, Egli RJ. Transforming growth factor Beta signaling is essential for the autonomous formation of cartilage-like tissue by expanded chondrocytes. PLoS One. 2015;10(3):e0120857. doi:10. 1371/journal.pone.0120857.

25. Wang CJ, Yang KD, Ko JY, Huang CC, Huang HY, Wang FS. The effects of shockwave on bone healing and systemic concentrations of nitric oxide (NO), TGF-beta1, VEGF and BMP-2 in long bone non-unions. Nitric oxide. 2009;20(4):298-303. doi:10.1016/j.niox.2009.02.006.

26. Gautschi OP, Frey SP, Zellweger R. Bone morphogenetic proteins in clinical applications. ANZ J Surg. 2007;77(8):626-31. doi:10.1111/j.14452197.2007.04175.x.

27. Takemoto R, Forman J, Taormina DP, Egol KA. No advantage to rhBMP-2 in addition to autogenous graft for fracture nonunion. Orthopedics. 2014;37(6): e525-30. doi:10.3928/01477447-20140528-51. 
28. Borrelli Jr J, Prickett WD, Ricci WM. Treatment of nonunions and osseous defects with bone graft and calcium sulfate. Clin Orthop Relat Res. 2003;411: 245-54. doi:10.1097/01.blo.0000069893.31220.6f.

29. Cho TJ, Gerstenfeld LC, Einhorn TA. Differential temporal expression of members of the transforming growth factor beta superfamily during murine fracture healing. J Bone Miner Res. 2002;17(3):513-20. doi:10. 1359/jbmr.2002.17.3.513

30. Giannoudis PV, Kanakaris NK, Dimitriou R, Gill I, Kolimarala V, Montgomery RJ. The synergistic effect of autograft and BMP-7 in the treatment of atrophic nonunions. Clin Orthop Relat Res. 2009;467(12):3239-48. doi:10. 1007/s11999-009-0846-2.

31. Moghaddam A, Zietzschmann S, Bruckner T, Schmidmaier G. Treatment of atrophic tibia non-unions according to 'diamond concept': Results of oneand two-step treatment. Injury. 2015;46 Suppl 4:S39-50. doi:10.1016/S0020 1383(15)30017-6.

32. Niikura T, Hak DJ, Reddi AH. Global gene profiling reveals a downregulation of BMP gene expression in experimental atrophic nonunions compared to standard healing fractures. J Orthop Res. 2006;24(7):1463-71. doi:10.1002/jor.20182.

33. Tim CR, Bossini PS, Kido HW, Malavazi I, von Zeska Kress MR, Carazzolle MF, et al. Effects of low-level laser therapy on the expression of osteogenic genes during the initial stages of bone healing in rats: a microarray analysis. Lasers Med Sci. 2015;30(9):2325-33. doi:10.1007/s10103-015-1807-5.

34. Buttner M, Moller S, Keller M, Huster D, Schiller J, Schnabelrauch M, et al. Over-sulfated chondroitin sulfate derivatives induce osteogenic differentiation of hMSC independent of BMP-2 and TGF-beta1 signalling. J Cell Physiol. 2013;228(2):330-40. doi:10.1002/jcp.24135.

35. Gerstenfeld LC1, Cullinane DM, Barnes GL, Graves DT, Einhorn TA. Fracture healing as a post-natal developmental process: Molecular, spatial, and temporal aspects of its regulation, (2003).

36. Binder H, Eipeldauer S, Gregori M, Hochtl-Lee L, Thomas A, Tiefenboeck TM, et al. The difference between growth factor expression after single and multiple fractures: preliminary results in human fracture healing. Dis Markers. 2015;2015:203136. doi:10.1155/2015/203136

37. Glueck M, Gardner O, Czekanska E, Alini M, Stoddart MJ, Salzmann GM, et al. Induction of osteogenic differentiation in human mesenchymal stem cells by crosstalk with osteoblasts. BioRes Open Access. 2015;4(1):121-30. doi:10. 1089/biores.2015.0002

38. Caplan Al, Correa D. PDGF in bone formation and regeneration: new insights into a novel mechanism involving MSCs. J Orthop Res. 2011;29(12): 1795-803. doi:10.1002/jor.21462.

39. Tan HB, Giannoudis PV, Boxall SA, McGonagle D, Jones E. The systemic influence of platelet-derived growth factors on bone marrow mesenchymal stem cells in fracture patients. BMC med. 2015;13:6. doi:10.1186/s12916-014-0202-6.

40. Hollinger JO, Hart CE, Hirsch SN, Lynch S, Friedlaender GE. Recombinant human platelet-derived growth factor: biology and clinical applications. J Bone Joint Surg Am. 2008:90 Suppl 1:48-54. doi:10.2106/JBJS.G.01231.

41. Tyndall WA, Beam HA, Zarro C, O'Connor JP, Lin SS. Decreased platelet derived growth factor expression during fracture healing in diabetic animals. Clin Orthop Relat Res. 2003;408:319-30.

42. Younger A, Wing K, Penner M, Cresswell M. A study to evaluate the safety of platelet-derived growth factor for treatment of osteochondral defects of the talus. Knee surgery, sports traumatology, arthroscopy : official journal of the ESSKA. 2015. doi:10.1007/s00167-015-3549-0.

43. Nash TJ, Howlett CR, Martin C, Steele J, Johnson KA, Hicklin DJ. Effect of platelet-derived growth factor on tibial osteotomies in rabbits. Bone. 1994; 15(2):203-8.

44. Chen T, Gomez AW, Zuo Y, Li X, Zhang Z, Li Y et al. Osteogenic potential and synergistic effects of growth factors delivered from a bionic composite system. Journal of biomedical materials research Part A. 2015. doi:10.1002/ jbm.a.35605

45. Saadeh PB, Mehrara BJ, Steinbrech DS, Spector JA, Greenwald JA, Chin GS, et al. Mechanisms of fibroblast growth factor-2 modulation of vascular endothelial growth factor expression by osteoblastic cells. Endocrinology. 2000;141(6):2075-83. doi:10.1210/endo.141.6.7502.

46. Hanada K, Dennis JE, Caplan Al. Stimulatory effects of basic fibroblast growth factor and bone morphogenetic protein-2 on osteogenic differentiation of rat bone marrow-derived mesenchymal stem cells J Bone Miner Res. 1997;12(10):1606-14. doi:10.1359/jbmr.1997.12.10.1606.
47. Kawaguchi H, Nakamura K, Tabata Y, Ikada Y, Aoyama I, Anzai J, et al. Acceleration of fracture healing in nonhuman primates by fibroblast growth factor-2. J Clin Endocrinol Metab. 2001;86(2):875-80. doi:10.1210/jcem.86.2.7199.

48. Chaudhary LR, Hofmeister AM, Hruska KA. Differential growth factor control of bone formation through osteoprogenitor differentiation. Bone. 2004; 34(3):402-11. doi:10.1016/j.bone.2003.11.014.

49. Nelson ER, Huang Z, Ma T, Lindsey D, Jacobs C, Smith RL, et al. New bone formation by murine osteoprogenitor cells cultured on corticocancellous allograft bone. J Orthop Res. 2008;26(12):1660-4. doi:10.1002/jor.20676.

50. Quarto N, Longaker MT. FGF-2 inhibits osteogenesis in mouse adipose tissue-derived stromal cells and sustains their proliferative and osteogenic potential state. Tissue Eng. 2006;12(6):1405-18. doi:10.1089/ten.2006.12.1405.

51. Tasso R, Gaetani M, Molino E, Cattaneo A, Monticone M, Bachi A, et al. The role of bFGF on the ability of MSC to activate endogenous regenerative mechanisms in an ectopic bone formation model. Biomaterials. 2012;33(7): 2086-96. doi:10.1016/j.biomaterials.2011.11.043.

52. Vo TN, Kasper FK, Mikos AG. Strategies for controlled delivery of growth factors and cells for bone regeneration. Adv Drug Deliv Rev. 2012;64(12): 1292-309. doi:10.1016/j.addr.2012.01.016.

53. Chen FM, Zhang M, Wu ZF. Toward delivery of multiple growth factors in tissue engineering. Biomaterials. 2010;31(24):6279-308. doi:10.1016/j. biomaterials.2010.04.053

54. Rice R, Rice DP, Thesleff I. Foxc1 integrates Fgf and Bmp signalling independently of twist or noggin during calvarial bone development. Dev Dyn. 2005;233(3):847-52. doi:10.1002/dvdy.20430.

55. Westhauser F, Zimmermann G, Moghaddam S, Bruckner T, Schmidmaier G, Biglari $B$, et al. Reaming in treatment of non-unions in long bones: cytokine expression course as a tool for evaluation of non-union therapy. Arch Orthop Trauma Surg. 2015;135(8):1107-16. doi:10.1007/s00402-015-2253-3.

\section{Submit your next manuscript to BioMed Central and we will help you at every step:}

- We accept pre-submission inquiries

- Our selector tool helps you to find the most relevant journal

- We provide round the clock customer support

- Convenient online submission

- Thorough peer review

- Inclusion in PubMed and all major indexing services

- Maximum visibility for your research

Submit your manuscript at www.biomedcentral.com/submit 